\title{
Analysis of the results of state land supervision by solving problems of mathematical statistics
}

\author{
Alexander Sizov ${ }^{1}$, Elena Chernykh ${ }^{2, *}$ \\ ${ }^{1}$ Moscow State University of Geodesy and Cartography, Moscow, 105064, Russia \\ ${ }^{2}$ Industrial University of Tyumen, 625001, Tyumen, Russia
}

\begin{abstract}
The aim of the study was to identify the relationship between indicators of state land supervision, land use and the receipt of taxes, fees and other payments to budgets of different levels. In this study, when analyzing the results of supervision and control measures in the field of land relations, non-trivial conclusions were obtained. Each detected violation of land legislation is accompanied in the Tyumen region by the registration of the corresponding protocol. A close relationship was found between the number of issued instructions and the number of violations detected $(r=0.87)$; the number of issued orders is closely correlated with the number of issued protocols $(\mathrm{r}=0.87)$. To a lesser extent, the revealed violations affect the amount of fines imposed $(r=0.63)$ and the area on which the violations were eliminated $(r=0.52)$. This suggests that the absolute increase in the number of identified violations does not have the proper impact on their elimination. The average strength of the relationship between the indicators of the amount of fines imposed for violations of land legislation and the area of the reserve land $(r=0.66)$ is established.
\end{abstract}

\section{Introduction}

It must be emphasized that land protection in the Russian Federation is not up to standard. The lack of measures for the prevention of land violations, methods for planning inspections for compliance with land legislation, the weak interaction of state authorities and local authorities leads to a low level of responsibility of users of land plots.

Land resources are the only living space and basis for the economic development of any country, therefore, in accordance with the Constitution of the Russian Federation, land resources within the borders of the state are used and protected under the current land legislation.

In order to prevent land deterioration for land users, the necessary environmental and other rules are established. Local authorities and state authorities control the exploitation of land within their competence and determine areas with special conditions for the use of the territory $[1,2]$.

The legislation of the Russian Federation introduced closely related concepts in the field of supervisory control measures: state land supervision and municipal land control, differing in the level of implementation (either by state bodies or local governments). The

* Corresponding author: chernyheg@tyuiu.ru 
Federal Law of December 26, 2008 No. 294-Ф3 “On the Protection of the Rights of Legal Entities and Individual Entrepreneurs in the Implementation of State Control (Supervision) and Municipal Control" does not distinguish between the concepts of "control" and "supervision". Today, land oversight and control functions are gradually being harmonized and gaining a new legal meaning, the concepts of "control" and "supervision" are beginning to differentiate.

As part of state land supervision, measures are being taken to conduct scheduled / unscheduled documentary and field inspections of legal entities and individual entrepreneurs who are users of land plots, scheduled (raid) inspections and administrative surveys of objects of land relations.

Scheduled inspections are carried out on the basis of a plan of inspections of legal entities and individual entrepreneurs for the next year, agreed with the prosecution authorities and approved by the bodies of land supervision and municipal control.

We have carried out a study of the relationship of indicators characterizing the results of the work of territorial bodies of land supervision (control) in the subject of the Russian Federation and which, in essence, are indicators of the regional system for assessing and forecasting the state and use of land, necessary for analysis and planning of the use of land resources of the subject of the Russian Federation. The theoretical justification of such relationships in the general context was first proposed by A. P. Sizov [5]. Our assessment of the results of state supervision in the region was carried out in such a way that, based on easily accessible open data, with minimal efforts, we obtain stable results that reflect the processes of violation of land legislation in the territory and restoration of land quality in the dynamics of its development.

In this vein, a theoretical justification of the relationship of indicators characterizing the results of the work of land supervision (control) bodies with indicators of the system for assessing and predicting changes in the properties of individual environmental components that reflect the state and use of land, calculated in the analysis and planning of the use of land resources of the constituent entities of the Russian Federation, is necessary..

\section{Methods of analysis and construction of algorithms}

The results of state land supervision (hereinafter - GZN) using the methods of mathematical statistics were analyzed for the Tyumen region, which is unique as a complex constituent entity of the Russian Federation, but quite representative, both quantitatively, including 1 region, 2 autonomous districts, 462 municipalities, and qualitatively, including land of all categories and types of land [3,4].

The initial analysis of the source data obtained from the report "On the State and Use of Land in the Tyumen Region in 2018" showed that the scope of work on the GZN in the Khanty-Mansi Autonomous Okrug and the Yamalo-Nenets Autonomous Okrug is piecewise and does not allow for the correct analysis of these materials in comparison with south TO.

Further research was carried out in 2 stages. At the first stage, statistical dependencies between the indicators of state supervision were revealed through a correlation analysis. Correlation analysis revealed the direction, shape and degree of tightness of the relationship between two random signs. During the analysis, those pairs of indicators were selected whose correlation coefficient turned out to be in one of the following intervals (table 1).

Table 1. Analysis of the strength of the relationship between variables. 


\begin{tabular}{|c|c|}
\hline The value of $\mathrm{r}$ (correlation coefficient) & $\begin{array}{c}\text { Interpretation of the relationship between } \\
\text { indicators }\end{array}$ \\
\hline $0.5-0.7$ & average \\
\hline $0.7-0.9$ & high \\
\hline $0.9-1$ & very high \\
\hline
\end{tabular}

Those pairs of indicators were accepted for consideration, the correlation coefficient between which fell at predetermined intervals and was positive, i.e. in the direction, the correlation is direct (positive - when the values of one variable increase, the value of the other increases).

\section{Research results}

The results of the 1 st stage are presented in table 2.

The data obtained in Table 2 indicate that a 100\% functional (absolute) relationship was revealed by a single pair of indicators ("the detected number of violations" and "the number of issued protocols", $\mathrm{r}=1$ ). The value of the linear correlation coefficient 1 indicates that each value of the detected number of violations strictly corresponds to the value of the number of issued protocols. In other words, the number of detected violations determines the number of issued protocols in $100 \%$ of cases $[5,6]$.

High communication strength was revealed between the following pairs of indicators: "number of violations detected" and "number of issued instructions" ( $\mathrm{r}=0.87)$; "Number of issued protocols" and "number of issued instructions" $(\mathrm{r}=0.87)$; "Amount of fines imposed" and "amount of fines collected" $(\mathrm{r}=0.85)$. The linear correlation coefficient in this range does not mean absolute, but a statistical relationship. The correlation between the "number of detected violations" and "issued prescriptions" is shown in Figure 1.

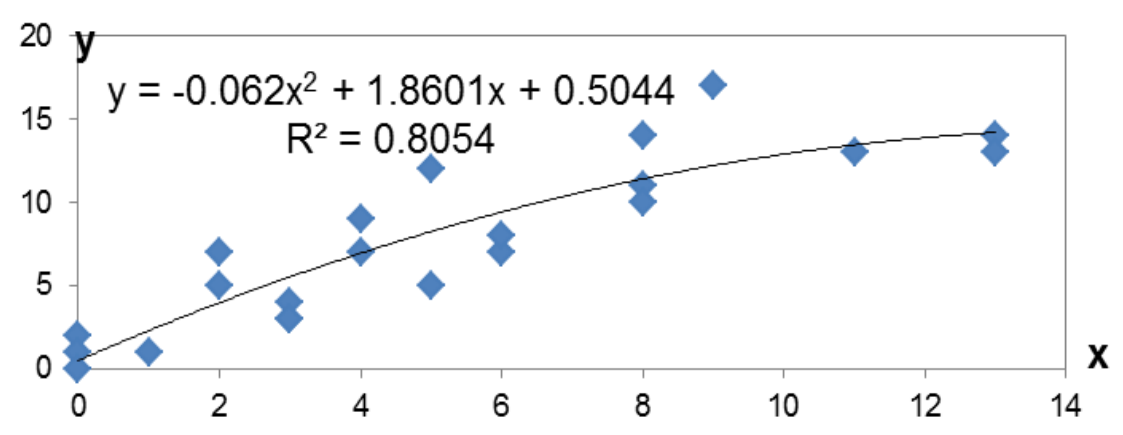

Fig. 1. A positive (direct) correlation between the number of issued instructions ( $\mathrm{X}$ axis, units) and the number of violations detected ( $\mathrm{Y}$ axis, units). Polynomial function: $\mathrm{y}=-0.062 \mathrm{x} 2+1.8601 \mathrm{x}+$ $0.5044 ; \mathrm{R}^{2}=0.8054$.

The number of detected violations also correlates with the amount of fines imposed $(\mathrm{r}=$ 0.63 ), showing the average communication strength, and even slightly less - with the area on which the violations were eliminated $(\mathrm{r}=0.52)$. It can be argued that, to a greater extent, with an increase in the number of detected violations, the amount of fines imposed increases, and the area on which violations are eliminated increases to a lesser extent (in almost half the cases).

The area on which violations are revealed, in turn, shows a closer relationship with the number of executed protocols $(\mathrm{r}=0.60)$, and the number of executed protocols with the 
amount of fines imposed $(\mathrm{r}=0.63)$. And similarly, the number of issued protocols only in half the cases determines the area on which violations are eliminated $(\mathrm{r}=0.52)$.

The number of issued orders also does not fully affect the number of cases brought to administrative responsibility $(r=0.52)$ and the amount of fines imposed $(r=0.56)$. The amount of fines imposed, in turn, half determines the number of violations eliminated $(\mathrm{r}=$ $0.52)$.

Separately, it is worth highlighting the relationship between the amount of fines collected and the area of municipalities (MO) $(r=0.54)$. According to the results of the analysis, the amount of fines collected is the only indicator that shows the relationship with the area of Moscow Region. The higher the area of the territory, the more fines are collected from it, which is quite natural with the same quality of work of the territorial bodies of state land supervision.

No correlation was found between the population indicators in the municipalities of the south of the Tyumen Region and the GBV indicators (the relationship is weak and in half of the cases is negative (reverse)).

Based on the results of the correlation analysis, it was concluded that the relationship between the indicators characterizing the detection of violations and fines is more pronounced; to a lesser extent, they are associated with the elimination of violations. We illustrate this graphically: Figure 2 shows the relationship between the number of violations detected and the area on which the violations were eliminated $(r=0.52)$.

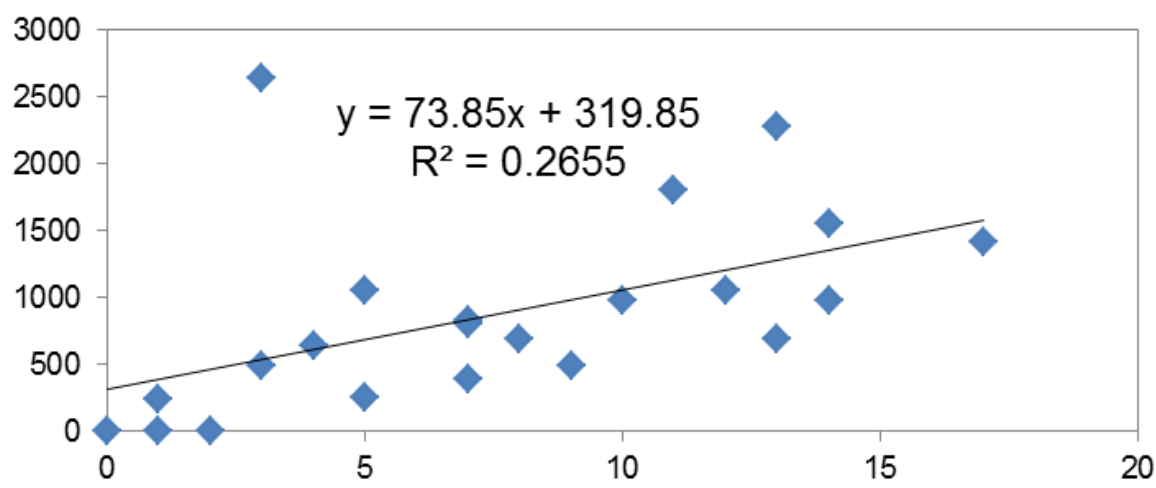

Fig.2. Dependence of the area on which violations are eliminated ( $\mathrm{Y}$ axis, ha) on the number of violations detected ( $\mathrm{X}$ axis, units). Linear function: $\mathrm{y}=73.85 \mathrm{~h}+319.85 ; \mathrm{R}^{2}=0.2655$.

Table 2. The correlation matrix of the tightness of the relationship between indicators of state land supervision and the development of territories in the south of the Tyumen region (as of 01/01/2019). 


\begin{tabular}{|c|c|c|c|c|c|c|c|c|c|c|c|c|}
\hline & 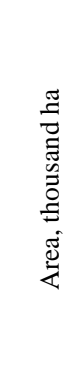 & $\frac{\frac{\Xi}{0}}{\frac{0}{0}}$ & 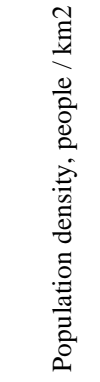 & 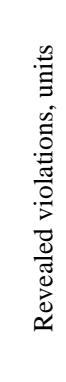 & 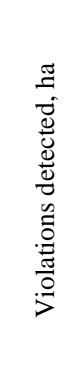 & 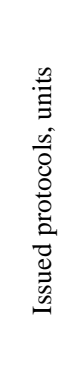 & 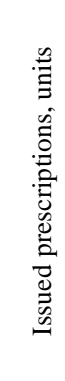 & 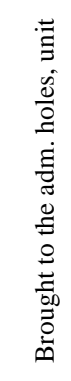 & 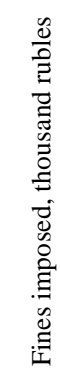 & 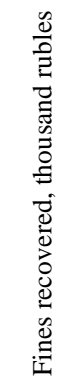 & 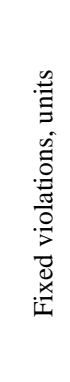 & 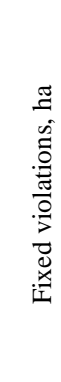 \\
\hline $\begin{array}{c}\text { Area, thousand } \\
\text { ha }\end{array}$ & 1.00 & & & & & & & & & & & \\
\hline Population & -0.04 & 1.00 & & & & & & & & & & \\
\hline $\begin{array}{c}\text { Population } \\
\text { density, people } \\
\text { / km2 }\end{array}$ & -0.27 & 0.95 & 1.00 & & & & & & & & & \\
\hline $\begin{array}{c}\text { Revealed } \\
\text { violations, } \\
\text { units }\end{array}$ & 0.35 & 0.29 & 0.14 & 1.00 & & & & & & & & \\
\hline $\begin{array}{l}\text { Violations } \\
\text { detected, ha }\end{array}$ & 0.16 & 0.40 & 0.36 & 0.60 & 1.00 & & & & & & & \\
\hline $\begin{array}{c}\text { Issued } \\
\text { protocols, units }\end{array}$ & 0.35 & 0.29 & 0.14 & 1.00 & 0.60 & 1.00 & & & & & & \\
\hline $\begin{array}{c}\text { Issued } \\
\text { prescriptions, } \\
\text { units }\end{array}$ & 0.49 & 0.14 & -0.0035 & 0.87 & 0.43 & 0.87 & 1.00 & & & & & \\
\hline $\begin{array}{l}\text { Brought to the } \\
\text { adm. holes, } \\
\text { unit }\end{array}$ & 0.14 & -0.18 & -0.17 & 0.28 & 0.09 & 0.28 & 0.52 & 1.00 & & & & \\
\hline $\begin{array}{c}\text { Fines imposed, } \\
\text { thousand } \\
\text { rubles }\end{array}$ & 0.40 & -0.11 & -0.25 & 0.63 & 0.16 & 0.63 & 0.56 & 0.06 & 1.00 & & & \\
\hline $\begin{array}{c}\text { Fines } \\
\text { recovered, } \\
\text { thousand } \\
\text { rubles }\end{array}$ & 0.54 & -0.16 & -0.34 & 0.48 & 0.08 & 0.48 & 0.50 & 0.19 & 0.85 & 1.00 & & \\
\hline $\begin{array}{c}\text { Fixed } \\
\text { violations, } \\
\text { units } \\
\end{array}$ & 0.08 & 0.01 & 0.00 & 0.39 & 0.17 & 0.39 & 0.35 & 0.47 & 0.52 & 0.32 & 1.00 & \\
\hline $\begin{array}{c}\text { Fixed } \\
\text { violations, ha }\end{array}$ & -0.07 & 0.16 & 0.17 & 0.52 & 0.24 & 0.52 & 0.47 & 0.17 & 0.42 & 0.11 & 0.44 & 1.00 \\
\hline
\end{tabular}

The determination coefficient $\left(\mathrm{R}^{\wedge} 2=0.269\right)$ of the model shown in Figure 2 indicates a low significance of the model, i.e. between indicators has a low linear relationship. This means that only in $26.9 \%$ of cases an increase in the number of detected violations will lead to an increase in the area on which they were eliminated. It also indicates that other factors influence the area with resolved violations [8].

In turn, we take a couple of indicators, the relationship between which is interpreted as strong (Figure 3). 


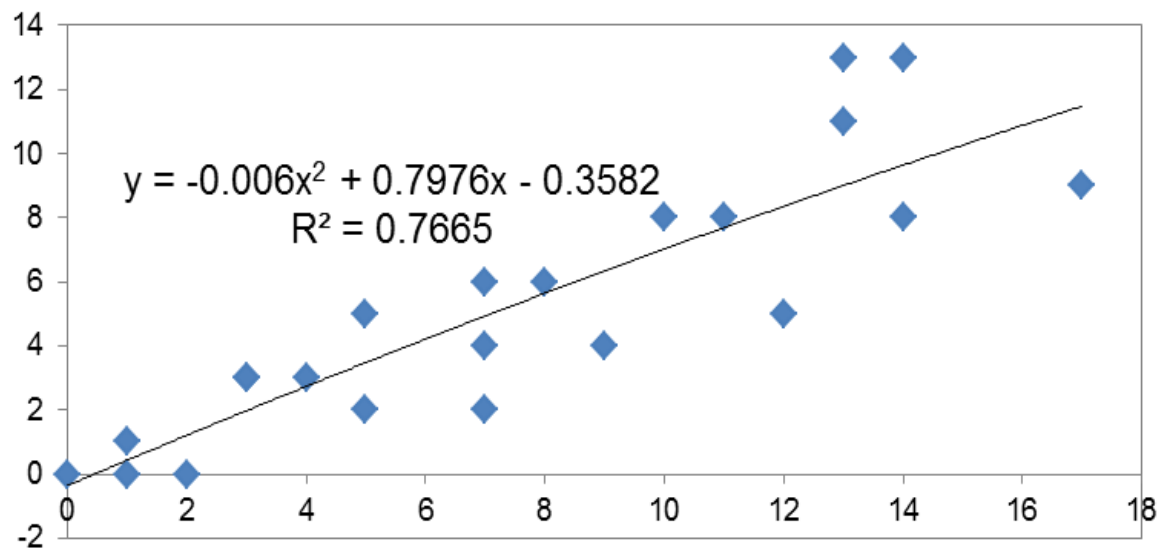

Fig. 3. Dependence of the number of issued instructions ( $\mathrm{Y}$ axis, units) on the number of violations detected (X axis, units). Polynomial function: $y=-0.006 x 2+0.7976 x-0.3582 ; R^{2}=0.767$.

This model, presented in Figure 3, will be the most significant, since in $76.7 \%$ of cases the number of issued instructions can be explained by the number of violations detected. It should be borne in mind that the number of issued orders is closely correlated with the number of violations detected $(\mathrm{r}=0.87)$.

At the second stage, a correlation and regression analysis of the indicators of state land surveillance with influencing factors was taken, which are indicators of land use in the municipalities of the south of the Tyumen region, taxes, fees and other mandatory payments to budgets of different levels.

No relationship was found between the indicators of taxes, fees and other obligatory payments with the indicators of other groups, in addition, the existing connection is negative, in other words, indicators from other groups grow with a low level of incoming taxes, but even such a connection is weak.

Between the indicators of land use and the indicators of GZN, no higher than average communication was found. A slightly closer relationship was found between the indicators of the amounts of fines imposed and the area of the reserve land $(r=0.66)$ (Figure 4).

As a result, we see that this model cannot be reliable, since in more than half of the cases, the dependent variable Y (in this example, this is the amount of fines imposed) will be influenced by other factors that are not taken into account in the presented model. However, among others, this pair showed the highest level of communication.

Based on the results of the second stage, we can conclude that the relationship between the indicators of GZN, land use and the receipt of taxes, fees and other payments to the budgets of different levels is not significant, which in turn indicates the need for more indepth studies of causal relationships for GZN indicators. 


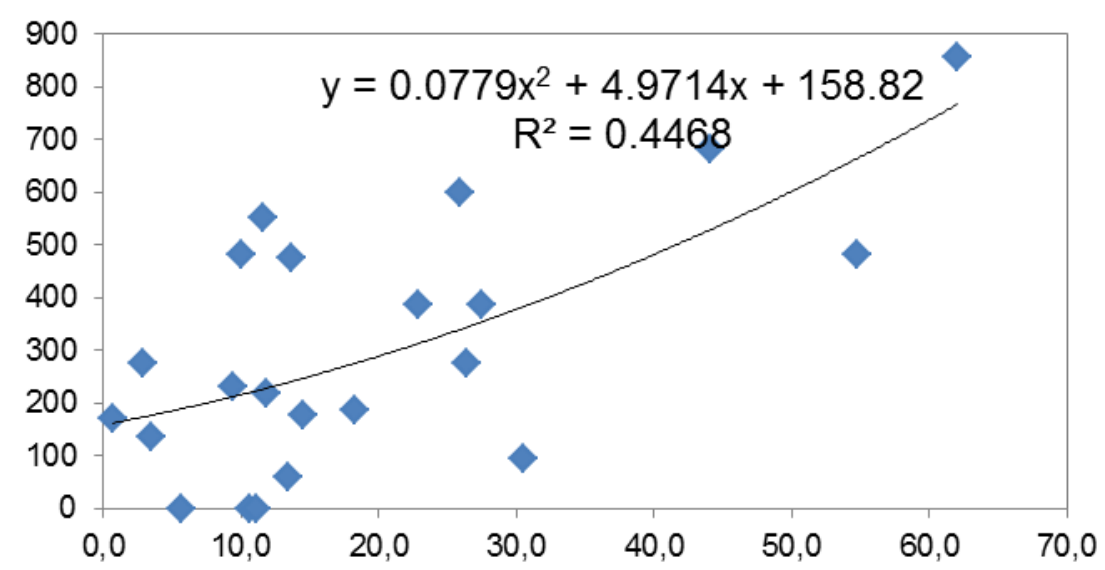

Fig. 4. Dependence of the amount of fines imposed ( $\mathrm{Y}$ axis, thousand rubles) on the area of reserve lands (X axis, thousand hectares). Polynomial function: $\mathrm{y}=0.0779 \times 2+4.9714 \mathrm{x}+158.82 ; \mathrm{R}^{2}=$ 0.4468 .

\section{Conclusions}

1) Each detected violation of land legislation is accompanied in the execution of the relevant protocol;

2) A close relationship was found between the number of issued orders and the number of detected violations $(\mathrm{r}=0.87)$, also the number of issued orders is closely correlated with the number of issued protocols $(\mathrm{r}=0.87)$. To a lesser extent, the revealed violations affect the amount of fines imposed $(\mathrm{r}=0.63)$ and the area on which the violations were eliminated $(\mathrm{r}=0.52)$. This suggests that the absolute increase in the number of identified violations does not have the proper impact on their elimination;

3) The average strength of the relationship between the indicators of the amount of fines imposed for violations of land legislation and the area of the reserve land $(r=0.66)$ was established;

4) Cases of administrative responsibility only $50 \%$ are determined by the number of issued orders;

5) A high connection is observed between the amounts of fines imposed and collected ( $\mathrm{r}$ $=0.85$ );

6) Close links between the main characteristics of municipalities in the south of the Tyumen region, the indicators of the State Tax Protection and the revenues of taxes, fees and other payments have not been identified.

\section{References}

1. A.P. Sizov, Geodesy and Cartography, 80, No. 10, 55-64 (2019) DOI: 10.22389 / 0016-7126-2019-952-10-55-64

2. E.G. Chernykh, A.P. Sizov, Use and protection of natural resources in Russia, No. 3 (159), 31-34 (2019)

3. Ch. Montgomery, Happy City: Transforming Our Lives through Urban Design (NY: Farrar, Straus, and Giroux, 2013)

4. M. Timberlake, Y. D. Wei, X. Ma, J. Hao, Cities, 41, 162-170 (2014) DOI:10.1016/j.cities.2014.02.009 
5. N. Ghodrati, Yiu T. Wing, S. Wilkinson, M. Shahbazpour, J. of Management in Engineering, 34 (6), 2018) doi.org/10.1061/(ASCE)ME.1943-5479.0000641

6. Information on the availability and distribution of land in the Russian Federation as of 01.01.2018 https://rosreestr.ru/site/activity/sostoyanie-zemel-rossii/gosudarstvennyynatsionalnyy-doklad-o-sostoyanii-i-ispolzovanii-zemel-v-rossiyskoy-federatsii/, last accessed 2019/12/21 